\title{
Pelatihan Microsoft Office dalam Pelaksanaan Tugas Administrasi Pemerintahan untuk Meningkatkan Kinerja Aparat Desa Sukanegara
}

\author{
Raka Andika Putra*1, Sigit Prabowo², Indah Purnamasari ${ }^{3}$
}

\begin{abstract}
1,2,3Program Studi Sistem Informasi, Fakultas Teknologi Informasi, Universitas Nusa Mandiri, Indonesia *e-mail: $\underline{\text { Andikaputraraka@gmail.com }}{ }^{1}$, Sigitprabowo448@gmail.com $^{2}$, indah.ihi@nusamandiri.ac.id $^{3}$
\end{abstract}

\begin{abstract}
Abstrak
Pemerintah desa sebagai bentuk pemerintah yang terendah dan langsung bersinggungan dengan masyarakat di tuntut untuk memberikan pelayanan yang terbaik sesuai kehendak masyarakatnya. Berdasarkan pengamatan awal team pendamping desa, Aparat Desa Sukanegara belum maksimal dalam pemanfaatan komputer yang sudah tersedia di kantor desa, karena keterbatasan ilmu pengetahuan di bidang komputer, sehingga masih sering menggunakan mesin ketik. Karena itu, permasalahan yang dihadapi Aparat Desa Sukanegara yaitu terhambatnya pengelolaan administrasi yang masih dikerjakan secara manual menyebabkan pelayanan kepada masyarakat menjadi kurang maksimal dan membutuhkan waktu cukup lama. Kami menggunakan Metode dengan melakukan survey ke lokasi Kantor Desa Sukanegara dan melakukan wawancara kepada Aparatur Desa Sukanegara tentang permasalahan yang dimiliki, dan hasilnya yaitu para Aparatur Desa Sukanegara belum pandai dalam menggunakan Microsoft Office untuk melaksanakan tugas administrasi pemerintahan sehingga menghambat dalam melakukan pelayanan terhadap masyarakat. Maka dari itu kami mengajukan kepada Aparatur Desa Sukanegara untuk melaksanakan Pelatihan penggunaan Microsoft Office khusunya Microsoft Word dan Excel agar mempermudah Aparatur Desa Sukanegara dalam menjalakan tugas administrasi Pemerintahan Desa. Kesimpulan dari hasil kegiatan pengabdian masyarakat yang telah dilaksanakan tentang Pelatihan Microsoft Office Dalam Pelaksanaan Tugas Administrasi Pemerintahan Untuk Meningkatkan Kinerja Aparatur Desa Sukanegara yaitu terdapat peningkatan pengetahuan dan kemampuan bagi para Aparatur Desa Sukanegara tentang cara menggunakan Microsoft Word dan Excel untuk menjalankan tugas administrasi pemerintahan, para Aparatur Desa Sukanegara menjadi lebih mudah dalam mengerjakan administrasi pemerintahan dan membuat surat yang lebih efektif sehingga bisa meningkatkan pelayanan kepada masyarakat Desa Sukanegara.
\end{abstract}

Kata kunci: Aparatur Desa, Pelatihan Microsoft Office, Pemerintahan Desa

\section{Abstract}

The village government as the lowest form of government and directly in contact with the community is required to provide the best service according to the wishes of the community. Based on the initial observations of the village assistance team, Sukanegara Village Officials have not maximized the use of computers that are already available at the village office, due to limited knowledge in the field of computers, so they still often use typewriters. Therefore, the problem faced by the Sukanegara Village Apparatus is the obstruction of administrative management which is still done manually, causing services to the community to be less than optimal and take quite a long time. We used the method by conducting a survey to the location of the Sukanegara Village Office and conducting interviews with the Sukanegara Village Apparatus about the problems they had, and the result was that the Sukanegara Village Apparatus were not yet good at using Microsoft Office to carry out government administration tasks, thus hampering their service to the community. Therefore, we propose to the Sukanegara Village Apparatus to carry out training on the use of Microsoft Office, especially Microsoft Word and Excel in order to make it easier for the Sukanegara Village Apparatus in carrying out village administration tasks. With this community service, the Sukanegara Village Office has increased knowledge and modern technology, one of which is the Microsoft Office application (Word and Excel) which is very helpful in government administration tasks. The conclusion from the results of community service activities that have been carried out regarding Microsoft Office Training in the Implementation of Government Administration Duties to Improve the Performance of the Sukanegara Village Apparatus is that there is an increase in knowledge and abilities for Sukanegara Village Apparatuses on how to use Microsoft Word and Excel to carry out government administration tasks, the Apparatus Sukanegara Village makes it easier to do government administration and make more effective letters so that they can improve services to the people of Sukanegara Village.

Keywords: Village Administration, Village Aparatus, Microsoft Office Trainning 


\section{PENDAHULUAN}

Pada Era digitalisasi saat ini sangat dibutuhkan user yang memiliki kemampuan lebih dalam mengolah berbagai macam format data menjadi bentuk softfile digital. Data yang sebelumnya terbentuk manual, saat ini diharapkan tersimpan sebuah storage dalam format softcopy. Pemerintah desa sebagai bentuk pemerintah yang terendah dan langsung bersinggungan dengan masyarakat di tuntut untuk memberikan pelayanan yang terbaik sesuai kehendak masyarakatnya. Karena itu, aparat desa juga di tuntut untuk bisa tanggap dalam pelaksanaan pekerjaannya khususnya dalam pelaksanaan tugas-tugas administrasi dalam pemerintahan, di samping memperkuat partisipasi masyarakat dan kelembagaannya serta aspek-aspek lainnya. Hal tersebut sangat penting karena pemerintah desa beserta aparatnya adalah sebagai administrator penyelenggara utama aktivitas pemerintahan, pembangunan dan kemasyarakatan maupun sebagai Pembina ketentraman dan ketertiban di wilayah kekuasaannya. Oleh sebab itu di perlukan aparat desa yang benar-benar mampu dan dapat bekerja sama dalam pelaksaan tugas adminstrasi yang menjadi tanggung jawabnya.

Keberadaan aparat desa yang juga diserahi tugas dibilang administrasi, menduduki posisi yang sangat penting karena sebagai organ pemerintahan yang paling bawah mengetahui secara pasti segala kondisi dan permasalahan yang ada di wilayahnya, maka input pada pemerintah kecamatan yang menyangkut berbagai keterangan dan informasi sangatlah dibutuhkan dalam pengambilan kebijaksanaan daerah maupun nasional untuk kebutuhan pembangunan secara menyeluruh. Dengan demikian aparat desa dalam pelaksanaan tugasnya sehari-hari, terutama yang berhubungan dengan penyajian data dan informasi yang dibutuhkan, semakin dituntut adanya kerja keras dan kemampuan yang optimal guna memperlancar pelaksanaan tugas pemerintahan. Dalam konteks penyelenggaraan pemerintahan desa yang terpenting adalah bagaimana pemerintahan desa mampu meningkatkan kesejahteraan rakyatnya, mampu memberikan pelayanan kepada masyarakat desa, dan mampu meningkatkan daya saing desanya. Hal tersebut hanya mungkin terwujud apabila urusan yang menjadi kewenangan desa dapat terlaksana dengan baik. Tidak dapat di pungkiri, bahwa dalam implementasinya terdapat berbagai permasalahan yang langsung maupun tidak langsung menghambat pelaksanaan urusan-urusan pemerintahan tersebut (Rosita \& Ardiantoro, 2018).

Desa Sukanegara yang terletak di Kecamatan Jonggol Kabupaten Bogor adalah lokasi binaan team penulis. Lokasi ini dipilih berdasarkan permintaan mitra sendiri yaitu aparat desa Sukanegara yang ingin meningkatkan kemampuan dibidang Microsoft Office khususnya pada Microsoft Word dan Excel agar bisa menunjang pelaksanaan tugas-tugas di kantor pemerintahan desa. Berdasarkan pengamatan awal team pendamping desa, aparat desa Sukanegara masih belum maksimal dalam pemanfaatan computer yang sudah tersedia di kantor desa, karena keterbatasan ilmu pengetahuan di bidang computer, sehingga masih sering menggunakan mesin ketik.

Oleh sebab itu, melalui kegiatan pelatihan penggunaan Microsoft Office untuk meningkatkan kemampuan Aparat Desa Dalam Pelaksanaan Tugas Administrasi Pemerintah Di Desa Sukanegara Kecamatan Jonggol Kabupaten Bogor merupakan perwujudan dari kegiatan Tri Dharma Perguruan Tinggi salah satunya yaitu Pengabadian Kepada Masyarakat.

\section{METODE}

Metode pelaksanaan yang digunakan dalam menyelesaikan permasalahan pada Aparatur Desa Sukanegara yaitu:

\subsection{Tahapan Perencanaan}

Pada Tahapan ini kami melakukan survey ke lokasi Kantor Desa Sukanegara dan melakukan wawancara kepada Aparatur Desa Sukanegara tentang apa permasalahan yang dimiliki, dan hasilnya yaitu para Aparatur Desa Sukanegara belum pandai dalam menggunakan Microsoft Office untuk melaksanakan tugas administrasi pemerintahan sehingga menghambat dalam melakukan pelayanan terhadap masyarakat. Maka dari itu kami mengajukan kepada 
Aparatur Desa Sukanegara untuk melaksanakan Pelatihan penggunaan Microsoft Office khusunya Microsoft Word dan Excel agar mempermudah Aparatur Desa Sukanegara dalam menjalakan tugas administrasi Pemerintahan Desa.

\subsection{Tahapan Persiapan}

Tahapan ini dilakukan untuk mengetahui permasalahan yang dihadapi oleh Aparatur Desa Sukanegara dalam melaksanakan tugas administrasi Pemerintahan dan mengajukan perijinan untuk melakukan kegiatan pelatihan Microsoft Office pada Aparatur Desa Sukanegara. Selanjutnya kami melakukan persiapan untuk melaksanakan pelatihan dengan membuat materi, menyiapkan alat-alat yang akan digunakan dan membuat schedule kegiatan pelatihan.

\subsection{Tahapan Pelaksanaan}

Pada tahapan ini kami melakukan pelatihan penggunaan Microsoft Office pada:

$\begin{array}{ll}\text { Hari } & : \text { Senin s/d Selasa } \\ \text { Tanggal } & : 06-07 \text { Desember } 2021 \\ \text { Waktu } & : 09.00 \text { s/d Selesai. } \\ \text { Lokasi } & : \text { Kantor Desa Sukanegara }\end{array}$

Adapun tahapan kegiatan pelatihan Microsoft Word dan Excel untuk meningkatkan kinerja Aparatur Desa Sukanegara diantaranya sebagai berikut:

a. Membuat jadwal pelatihan dengan melakukan koordinasi dengan Kepala Desa di Desa Sukanegara Kecamatan Jonggol.

b. Menyiapkan alat dan bahan pelatihan berupa modal untuk kegiatan pelatihan Microsoft Word dan Excel.

c. Menyiapkan materi yang akan dibahas serta dibagikan kepada Aparatur Desa Sukanegara.

d. Melakukan evaluasi dengan Kantor Desa terhadap hasil yang dilakukan dalam pelaksanaan kegiatan pelatihan penggunaan Microsoft Office dengan melakukan kunjungan ke Kantor Desa Sukanegara.

Metode pelatihan yang digunakan dalam kegiatan ini adalah berupa pelatihan yang diawali dengan memberikan pengetahuan dasar tentang Microsoft Word dan Excel baik definisi, kegunaan dan fungsi-fungsinya serta tekniknya. Kemudian melakukan pelatihan bagaimana langkah untuk menjalankan system operasi Microsoft Word dan Excel antara lain sebagai berikut:

a. Mengetahui dan mempraktekkan langkah dasar dalam menjalankan Microsoft Word dan Excel.

b. Melakukan praktek membuat ketikan dan menyimpan file yang sudah di ketik.

c. Melakukan praktek membuka file yang telah tersimpan di dalam computer.

d. Melakukan praktek copy dan paste pada file yang akan dibuat.

e. Melakukan praktek menggabungkan kotak tabel, menambahkan kolom dan baris serta cara mencetak dalam Microsoft Excel.

f. Melakukan praktek pembuatan data ATK Kantor Desa.

g. Melakukan praktek pembuatan surat.

h. Melakukan praktek membuat laporan keuangan, anggaran dan penerimaan keuangan.

Selanjutnya menggunakan metode sharing dan diskusi yang dilakukan untuk memberikan kesempatan kepada peserta untuk bertanya dan kemudian akan diberikan solusi dan masukan oleh tim pengabdian kepada masyarakat dari Universitas Nusa Mandiri.

\subsection{Tahapan Monitoring dan Evaluasi}

Pada tahap ini kami menyerahkan soal tes yang harus di isi oleh Aparatur Desa Sukanegara yang bertujuan untuk mengetahui seberapa besar peningkatan kemampuan Aparatur Desa Sukanegara setelah dilakukannya pelatihan. Selain itu, Aparatur Desa Sukanegara juga harus mengisi kuesioner untuk mengetahui bagaimana respon dari peserta pelatihan. 


\section{HASIL DAN PEMBAHASAN}

Dengan adanya pengabdian masyarakat ini pihak Kantor Desa Sukanegara bertambah ilmu pengetahuan dan teknologi masa kini salah satunya yaitu aplikasi Microsoft Office (Word dan Excel) yang sangat membantu dalam tugas administrasi pemerintahan Kantor Desa Sukanegara yang di kerjakan oleh para Aparatur Desa. Dengan adanya pelatihan penggunaan Microsoft Word dan Excel kepada Aparatur Desa Sukanegara akan mempermudah dalam melakukan tugas administrasi pemerintahan serta lebih efektif dalam memberikan pelayanan kepada masyarakat Desa Sukanegara. Sukanegara:

Berikut adalah dokumentasi pelatihan Microsoft Word dan Excel pada Aparatur Desa

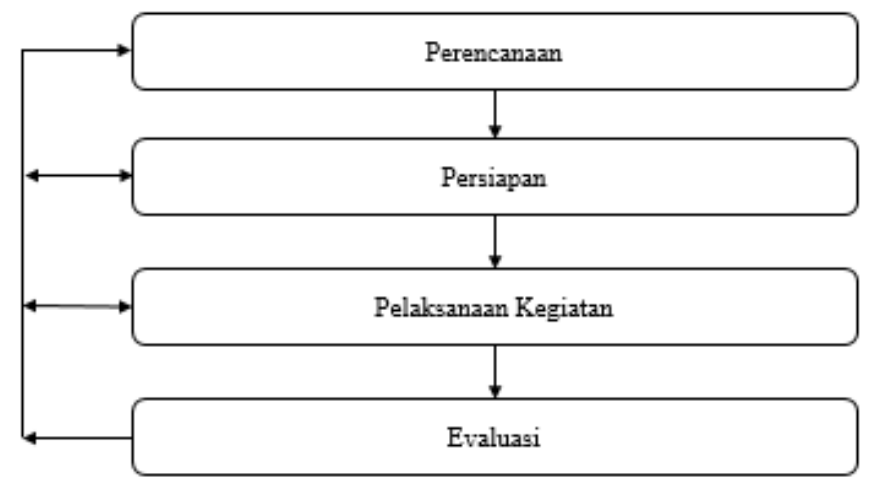

Gambar 1. Kerangka Kegiatan

Berikut gambar di atas menjelaskan kerangka kegiatan dalam menyelesai kan permasalahan aparatur desa sukanegara yang menggunakan metode perencanaan kemudian persiapan, pelaksanaan kegiatan dan evaluasi.

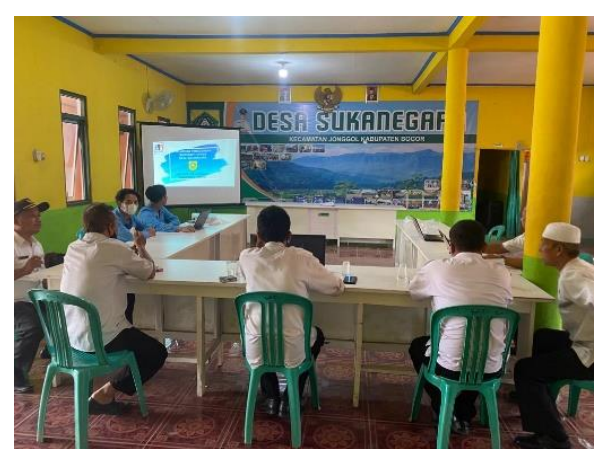

Gambar 2. Dokumentasi Pelatihan

Berikut Gambar 2 di atas dokumentasi pelatihan yang dimana sedang menjelaskan materi pelatihan kepada aparatur desa sukanegara.

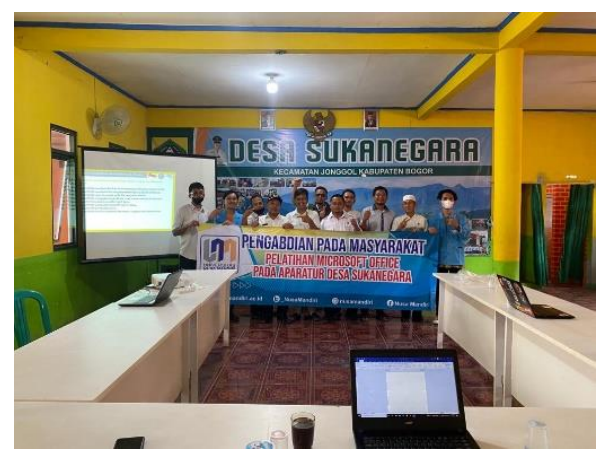

Gambar 3. Dokumentasi Pelatihan 
Berikut Gambar 3 di atas adalah dokumentasi selesainya pelatihan dan berfoto bersama dengan aparatur desa sukanegara yang mengikuti pelatihan.

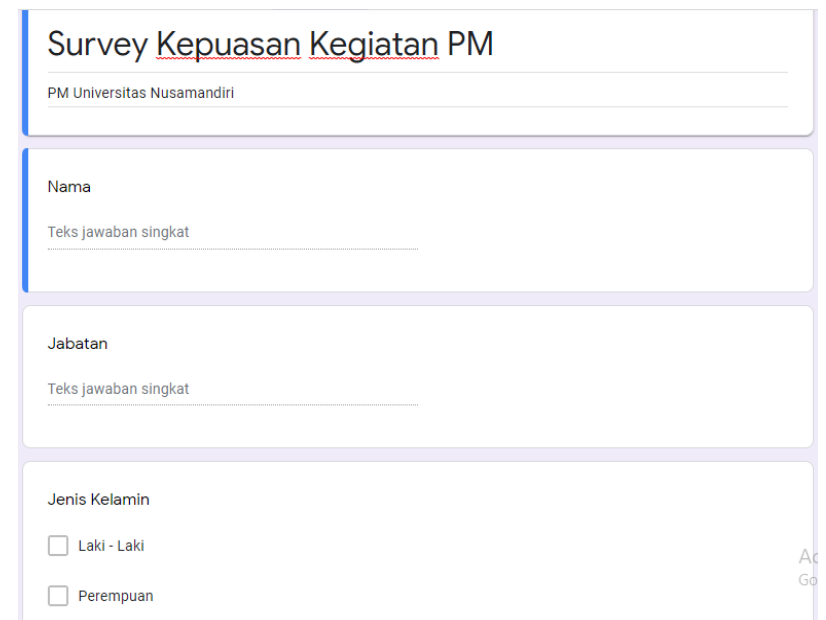

Gambar 4. Kusioner Survey Kepuasan Kegiatan PM

Gambar 4 survey kepuasan kegiatan pm dengan mengisikan nama aparatur, jabatan aparatur dan jenis kelamin aparatur.

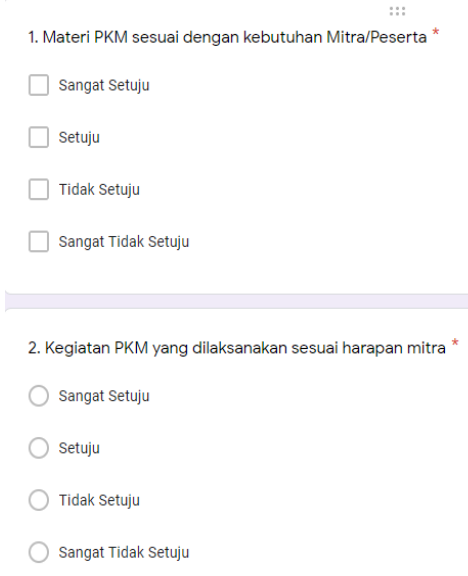

Gambar 5. Kusioner Survey Kepuasan Kegiatan PM

Gambar 5 isi dan pertanyaan kusioner survey kepuasan kegiatan pm.

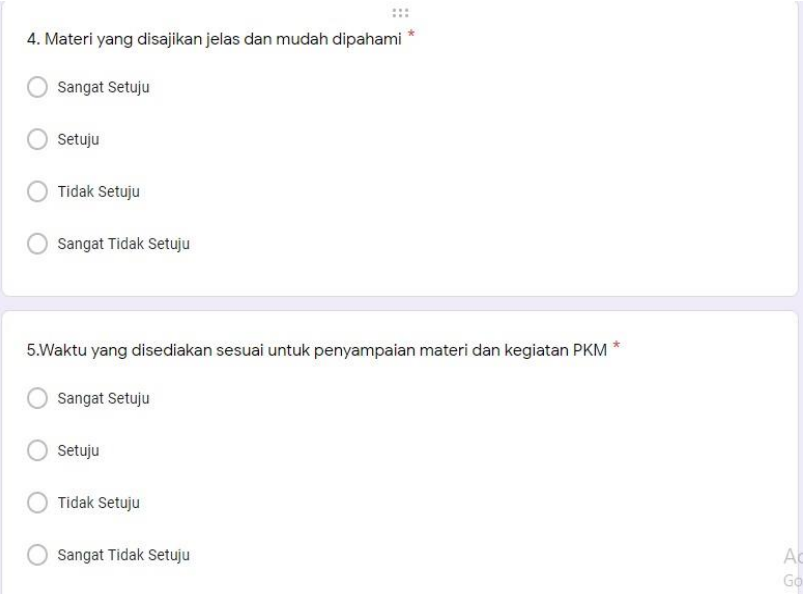

Gambar 6. Kusioner Survey Kepuasan Kegiatan PM 
Gambar 6 isi dan pertanyaan kusioner survey kepuasan kegiatan pm.

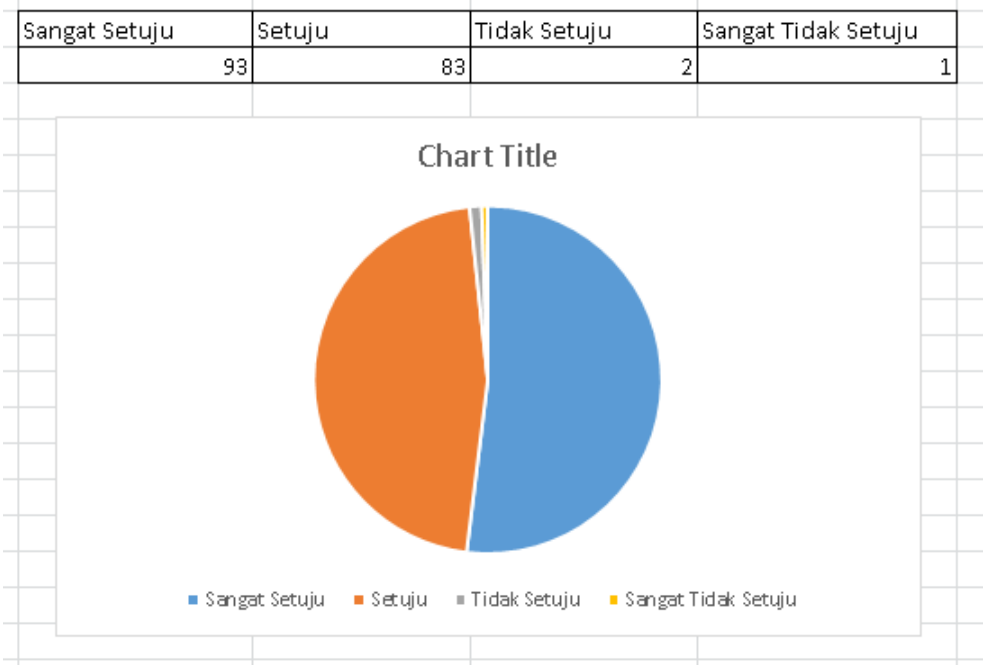

Gambar 7. Hasil Char Title Survey Kepuasan Kegiatan PM

Gambar 7 hasil dari kusioner survey kepuasan kegiatan pm yang terdiri dari hasil yang sangat setuju, setuju, tidak setuju dan sangat tidak setuju.

\section{KESIMPULAN}

Kesimpulan dari hasil kegiatan pengabdian masyarakat yang telah dilaksanakan tentang Pelatihan Microsoft Office Dalam Pelaksanaan Tugas Administrasi Pemerintahan Untuk Meningkatkan Kinerja Aparatur Desa Sukanegara sebagai berikut:

a. Terdapat peningkatan pengetahuan dan kemampuan bagi para Aparatur Desa Sukanegara tentang cara menggunakan Microsoft Word dan Excel untuk menjalankan tugas administrasi pemerintahan.

b. Para Aparatur Desa Sukanegara mendapat tambahan wawasan pada materi yang disampaikan dalam menggunakan teknologi masa kini salah satunya yaitu Aplikasi Microsoft Word dan Excel.

c. Para Aparatur Desa Sukanegara menjadi lebih mudah dalam mengerjakan administrasi pemerintahan dan membuat surat yang lebih efektif sehingga bisa meningkatkan pelayanan kepada masyarakat Desa Sukanegara.

\section{DAFTAR PUSTAKA}

Batjalery, S. (2019). ANALISA BAURAN PEMASARAN (7P) UNTUK MENENTUKAN STRATEGI PEMASARAN DALAM MENINGKATKAN VOLUME PEBatjalery, S. (2019). ANALISA BAURAN PEMASARAN (7P) UNTUK MENENTUKAN STRATEGI PEMASARAN DALAM MENINGKATKAN VOLUME PENJUALAN (Studi Kasus Pada HomeIndustry CV Mel. Jurnal Progresif Manajemen Bisnis (Jipmb), VI(4), 2354-5682. https://doi.org/10.35724/jies.v7i2.507

Lestari, P. A., \& Lestari, N. P. E. B. (2019). Pelatihan Aplikasi Perkantoran Menggunakan Microsoft. Jurnal Lentera Widya, 1(1), 30-34.

Putri, A. S., Pembimbing, I., Budiman, B., Si, M., \& Pmebimbing, D. (2014). PERENCANAAN PENELITIAN DAN PENGEMBANGAN (BAPELITBANG) KABUPATEN PENAJAM PASER UTARA.

Rokhman, M. M., Wibowo, S. A., Pranoto, Y. A., \& Widodo, K. A. (2018). Pelatihan Pemanfaatan Microsoft Office Pada Staf Pengajar Di SMPLBN (Sekolah Menengah Pertama Luar Biasa Negeri) Kota Malang. Jurnal Mnemonic, 1(1), 4-9. 
Rosita, Y. D., \& Ardiantoro, L. (2018). Pelatihan Pemrograman Aplikasi Microsoft Office Sebagai Bentuk Pengembangan Iptek Remaja. Seminar Nasional Sains Dan Teknologi Terapan, 625630.

Rusmulyani, K. (2020). Study Pengembangan Pendidikan Dan Pelatihan. Susunan Artikel Pendidikan, 5(2), 101-108.

Salam, A., \& Iqbal, T. (2020). IbM Pelatihan Microsoft Office Dalam Rangka Membentuk Masyarakat Yang Profesional. Jurnal Pengabdian Nasional (JPN) Indonesia, 1(1), 10-15. https://doi.org/10.35870/jpni.v1i1.2

Sari, R., Fitriyani, A., \& Prabandari, R. D. (2020). Optimalisasi Penggunaan MS. Word dan MS. Excel Pada Siswa SMP PGRI Astra Insani Bekasi. Jurnal Pengabdian Kepada Masyarakat UBJ, 3(2), 95-104. https://doi.org/10.31599/jabdimas.v3i2.184

Structures, M. B. (n.d.). Dr. Ramlan, SH, M.Hum, Dr. Eka N. A. M Sihombing, SH, M.HUm. (2021). "Hukum Pemerintahan Desa". Jl. Binjai Km. 5,5 No. 202A Medan (E. Asmadi (ed.); Pemerintah). Enam Media. 


\section{Halaman Ini Dikosongkan}

